\title{
The fornix in mild cognitive impairment and Alzheimer's disease
}

\section{Milap A. Nowrangi * and Paul B. Rosenberg}

Department of Psychiatry and Behavioral Sciences, Johns Hopkins University School of Medicine, Baltimore, MD, USA

Edited by:

Fernanda Laezza, University of Texas Medical Branch, USA

\section{Reviewed by:}

Bogdan O. Popescu, Colentina Clinical Hospital, Romania

Shin Murakami, Touro University

California, USA

\section{*Correspondence}

Milap A. Nowrangi, Department of Psychiatry, Johns Hopkins Bayview Medical Center, 5300 Alpha Commons Drive, 4th Floor, Baltimore, MD 21224, USA

e-mail:mnowran1@jhmi.edu
The fornix is an integral white matter bundle located in the medial diencephalon and is part of the limbic structures. It serves a vital role in memory functions and as such has become the subject of recent research emphasis in Alzheimer's disease (AD) and mild cognitive impairment (MCI). As the characteristic pathological processes of AD progress, structural and functional changes to the medial temporal lobes and other regions become evident years before clinical symptoms are present. Though gray matter atrophy has been the most studied, degradation of white matter structures especially the fornix may precede these and has become detectable with use of diffusion tensor imaging (DTI) and other complimentary imaging techniques. Recent research utilizing DTI measurement of the fornix has shown good discriminability of diagnostic groups, particularly early and preclinical, as well as predictive power for incident $\mathrm{MCl}$ and $\mathrm{AD}$. Stimulating and modulating fornix function by the way of DBS has been an exciting new area as pharmacological therapeutics has been slow to develop.

Keywords: Alzheimer's, MCI, fornix, DTI, DBS

\section{INTRODUCTION}

Alzheimer's disease $(\mathrm{AD})$ is the most common neurodegenerative condition in aging. $\mathrm{AD}$ is a growing public health problem that is projected to reach epidemic proportions if disease-modifying therapies are not found. The latest figures from the Alzheimer's Association indicate that there are an estimated 5.3 million Americans living with AD. By 2050, an estimated 11-16 million people are expected to be diagnosed in the United States alone (Thies et al., 2013). Establishing the diagnosis of Mild Cognitive Impairment (MCI) and $\mathrm{AD}$ has evolved over the last 25 years with the most recent iteration of the National Institute on Aging and Alzheimer's Association criteria (Mckhann et al., 1984, 2011). These criteria place a new emphasis on the use of biomarkers of $\mathrm{AD}$ pathophysiology whereas the original criteria were based solely on the clinical evaluation. Although the use of biomarkers to establish diagnosis or track progression is considered a step forward in the field, there is a need for continued development of complementary technologies utilizing biological, physical, cognitive, and behavioral substrates.

Broadly, the initial pathologic changes in $\mathrm{AD}$ have been shown to involve the medial temporal lobes with the accumulation of neurofibrillary tangles and senile beta amyloid plaques (Bancher et al., 1993; Braak and Braak, 1995; Xu et al., 2000; Braak et al., 2006). This region is thought to mediate the retrieval and learning of semantic and episodic memory - the most common early cognitive deficits in AD (Aggleton and Brown, 1999; Behl et al., 2005; Levy and Chelune, 2007; Baldwin and Farias, 2009). The accumulation of tangles and plaques is associated with progressive atrophy of the cortical gray matter as loss of large pyramidal neurons (layers III and IV) advances, particularly in cortical association regions (Braak and Braak, 1995). In addition to this, several white matter (WM) abnormalities have been described and are thought to reflect axonal disintegration, rarefaction, oligodendrocytosis, and astrocytosis (Xu et al., 2001; Roher et al., 2002; Shahani et al., 2002). Neuroimaging techniques, particularly magnetic resonance imaging (MRI), is a robust method used to visualize and detect subtle changes in structure and function of the substructures within the medial temporal lobe and related regions as important and perhaps early markers of disease and progression.

Though most volumetric imaging studies focused on atrophy of the entorhinal cortex and hippocampus, close inspection of the limbic structures has revealed significant volume reductions in patients with sporadic and familial AD (Decarli, 2001; Cash et al., 2013). The fornix is one structure within the limbic system that is receiving increasing attention recently in part because of its ease of detectability using MRI scanning as well as robust associations to cognitive changes, diagnostic group discrimination, and susceptibility to therapeutic intervention (Aggleton and Brown, 1999; Thomas et al., 2011). Because of the increasing interest in this structure, this brief review will serve as an updated survey of the key research over the last 10 years involving the fornix with hopes for continued and increasing efforts to better understand the use of this structure in the diagnosis, progression, and treatment of AD.

\section{FORNIX - STRUCTURE AND FUNCTION}

The fornix is a WM bundle belonging to the medial diencephalon, which also includes the hippocampus, mammillary bodies, and anterior and medial thalamus. Grossly, the fornix is found on the medial aspects of the cerebral hemispheres connecting the medial temporal lobes to the hypothalamus. It is formed at first from the output fibers of the hippocampus in the mesial temporal lobe, beneath the floor of the lateral ventricle. It courses along the curve of the corpus callosum forming its body. At the level of the foramen of Monro, the fornix divides and travels inferiorly and posteriorly 
in the lateral wall of the third ventricle to end in the hypothalamus and basal forebrain. Though the left and right fornices travel separately along their course from the hippocampus to the hypothalamus, they merge at the level of the forniceal body to form an important commissural tract (Nolte, 1993; Aggleton and Brown, 1999; Brewer, 2003; Patestas Ma, 2006). See Figures 1A,B.

The fornix is but one structure within the "temporal lobe memory system" also termed the Papez circuit described by James Papez in 1937 (Papez, 1995). The fornix has been demonstrated as the link between the hippocampus, mammillary bodies of the hypothalamus, and the anterior thalamic nuclei (via the mammilothalamic tract) (Nolte, 1993; Yamada et al., 1998; Aggleton and Brown, 1999; Patestas Ma, 2006). Efferent projections from the hippocampus to the medial diencephalon, particularly the anterior thalamic nuclei, are thought to be essential for normal hippocampal activity and are directed by the fornix, which then forms the major cholinergic output tract for the hippocampus (Cassel et al., 1997; Aggleton and Brown, 1999). Some of the earliest research involving lesion studies of this system asserted that damage to this axis resulted in anterograde amnesia, which occurs as a result of faulty encoding of episodic information (Aggleton and Brown, 1999). Specifically, damage to the hippocampus, fornix, and other diencephalic structures result in the inability to form declarative (semantic and episodic) memories. Although selective damage of the fornices has been shown to result in anterograde amnesia, the damage to other structures within the Papez circuit result in similar deficits emphasizes that the integrity of the circuit rather than individual substructure is important.

\section{FORNIX AS AN IMAGING BIOMARKER IN MCI AND AD}

There has been increasing research in recent years on imaging the fornix as a biomarker for diagnosis, progression (or conversion), and cognition in MCI and AD. Some of the earliest research focused on fornix ultrastructure as a sign of MCI and AD. Much of this research employed MRI volumetric methods and showed atrophy (volume reduction) in many of the limbic lobe structures including the fornix. Early volumetric studies by Callen et al. (2001) showed that a number of structures within the Papez circuit (hippocampus, amygdala, anterior thalamus, hypothalamus, mammillary bodies, basal forebrain, septal area, fornix, orbitofrontal, and parahippocampal cortices) suffered significant atrophy with hippocampal and posterior cingulate regions being particularly affected. These early studies largely established complimentary findings to neuropathological observations of limbic atrophy in AD (Hopper and Vogel, 1976). The interest in establishing morphological changes in preclinical $\mathrm{AD}(\mathrm{MCI})$ as an early marker of disease was first undertaken by Copenhaver et al. (2006) who did not show significant atrophy of fornix or mammillary bodies in MCI as was initially hypothesized. The inability to show this difference was likely due to the relative insensitivity of volumetric methods used at the time even though imaging processes and analyses were improved upon compared to similar
A

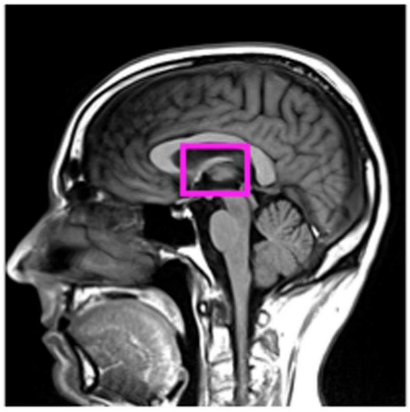

B

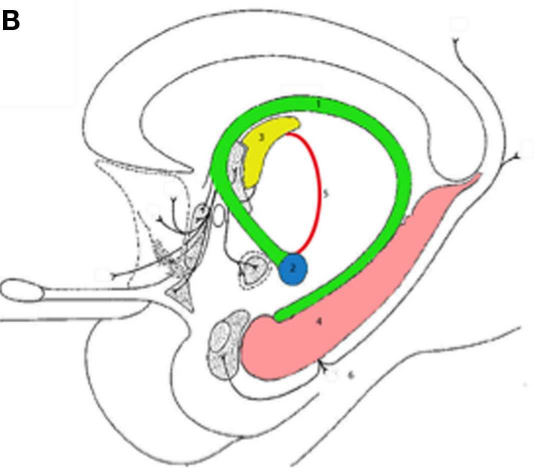

C Fornix Sign (-)

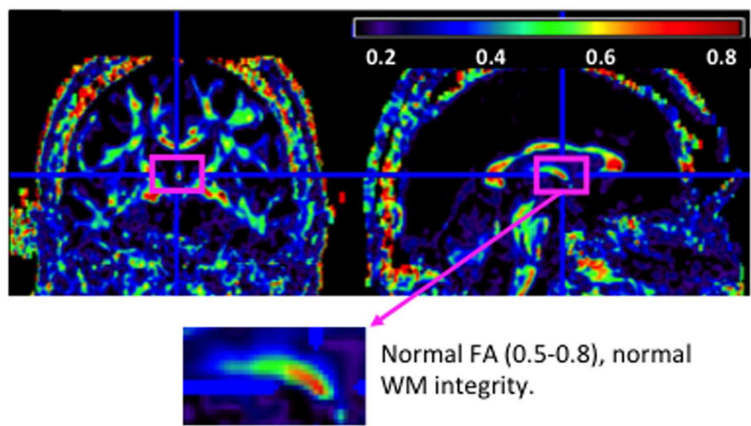

D Fornix Sign (+)

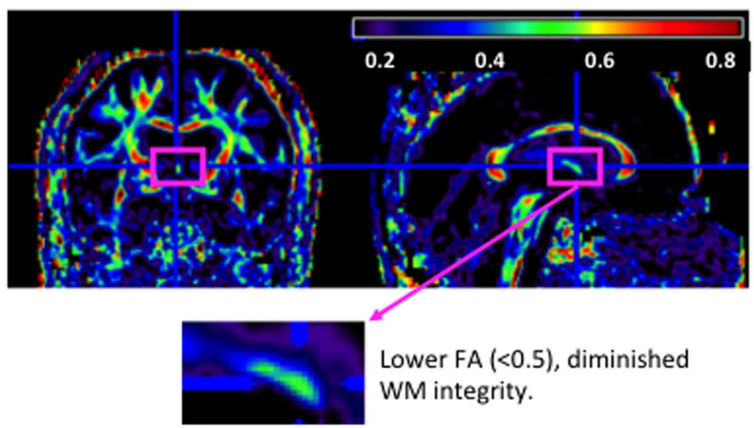

FIGURE 1 |The fornix anatomy and DTI fornix sign. (A) Normal neuroanatomy highlighting limbic structures. (B) 1. Fornix; 2. mammilary body; 3. anterior thalamic nucleus; 4. hippocampus; 5 . mammillothalamic tract; and 6. entorhinal cortex. Adapted from Nieuwenhuys (2008). (C) FA map of cognitively normal 80-year-old woman without fornix sign. (D) FA map of 80-year-old woman with Alzheimer's disease with fornix sign. (C,D) FA maps shown with magnified view of the fornix (fuchsia rectangle), adapted from Oishi et al. (2011). 
previous studies (Gale et al., 1993; Bilir et al., 1998; Kuzniecky et al., 1999; Callen et al., 2001). As a result, most recent research in the area has focused on fornix microstructure as the measurement of WM integrity. This renewed direction in imaging research of the fornix was based on the hypothesis that the earliest morphological changes occurred within medial temporal lobe gray matter, specifically the hippocampus and entorhinal structures with secondary effect to the efferent outflow tract through the fornix and mammillary bodies (Braak and Braak, 1995; Cassel et al., 1997; Aggleton and Brown, 1999). Needless to say, the underlying pathological processes affect an interconnected network of regions rather than single regions.

Diffusion tensor imaging has been the most commonly used in vivo MRI technique in studying the $\mathrm{WM}$ architecture of the fornix. Diffusion tensor imaging (DTI) is an indirect method of measuring WM integrity when conventional MRI lacks the contrast to delineate WM fiber tract organization (Beaulieu et al., 1996; Mori et al., 1999; Basser and Jones, 2002). Fractional anisotropy (FA) and mean diffusivity (MD) are two DTI measures used to quantify the integrity of WM microstructure by measuring the relative random motion of water in cerebral tissue. These measures are scalar values where higher values of FA and lower values of MD are thought to represent normal tissue cytoarchitecture where the random motion of water along a healthy axon, for example, is tightly constrained and restricted to movement along one direction (anisotropic). Two additional measures, axial diffusivity (DA) and radial diffusivity (DR) are associated with secondary degeneration of axons and breakdown of myelin and may provide additional detail into WM fiber integrity (Pierpaoli et al., 1996; Song et al., 2003, 2004).

Relating DTI measurement with other biomarkers that are considered more direct ways of detecting $\mathrm{AD}$ pathology has shown good correlation and has been a means of test validation. PET amyloid imaging is a well-established method of directly measuring $\mathrm{AD}$ pathology, $\beta$-amyloid $(\mathrm{A} \beta)$ deposition in vivo, but clinical application has been limited by convenience of use, invasiveness, and the half-life of radiotracers. When compared with DTI, several studies have shown positive correlation. A study by Chao et al. (2013) showed $A \beta$ deposition as measured by Pittsburgh compound B (PiB) PET imaging was associated with reduced WM integrity (lower FA) in the fornix and splenium of the corpus callosum in subjects who ranged from normal to MCI. Similarly, Racine et al. (2014) showed a positive correlation between $\mathrm{A} \beta+$ subjects and those with lower FA in the corpus callosum, hippocampal cingulum, and lateral fornix. Comparison with CSF markers of $A D$ pathology $A \beta_{42}$ and $p-T_{181}$ has also been an important area of research. A study by Gold et al. (2014) showed a positive correlation between these CSF markers and WM integrity (FA) in the fornix, a relationship that persisted after controlling for hippocampal and fornix volume in a cohort of 20 cognitively normal older adults. Lower FA in the fornix was also associated with reduced performance on several cognitive tests including a Digit Symbol Test. This study is particularly important because CSF changes are thought to precede neuroimaging alterations by several years (Jack et al., 2010). These studies strongly suggest that microstructural measurements are related to $\mathrm{AD}$ pathology.
As the interest in the field of identifying early markers of AD continued to grow, several studies aimed to identify WM changes in preclinical $\mathrm{AD}$. One of the earlier studies by Ringman et al. (2007) found decreased FA in the columns of the fornix were associated (linear regression) with hippocampal atrophy $(p=0.023)$, WM volume $(p=0.002)$, and mutation status $(p=0.032)$ in asymptomatic familial AD. They concluded that decreased FA in the forniceal columns is a robust finding in early familial $\mathrm{AD}$ and may be a biomarker of early disease in sporadic AD. Since this important study, there have been a number of more recent DTI studies showing similar associations between the WM tracts of the fornix and earlier preclinical stage. Cross-sectional DTI analysis by Mielke et al. (2009) and longitudinal analysis of the same cohort by Nowrangi et al. (2013) showed significant differences between normal participants and those with MCI and $\mathrm{AD}$ in the fornix, anterior cingulum, and splenium cross-sectionally and longitudinally $(p<0.01)$. Decreases in FA cross-sectionally and increases in MD longitudinally were observed in the fornix and were thought to indicate early markers of disease and longitudinal disease progression. Studies by Huang et al. (2012) and Boespflug et al. (2013) offered full DTI characterization (FA, MD, $\mathrm{DA}$, and DR) of region of interest and atlas-based approaches to $\mathrm{WM}$ analysis respectively in $\mathrm{MCI}$ and $\mathrm{AD}$. Both studies showed selective disruption of WM integrity in limbic structures including the fornix with DR being most sensitive to changes in the fornix. These studies further highlight a robust association between loss of integrity within the limbic structures and decrease in cognitive performance as illustrated by neuropsychological tests of episodic memory. Taken together, these studies suggest that the limbic WM tracts are preferentially affected in the early stages of cognitive dysfunction and that microstructural degradation of the fornix may precede atrophy of the hippocampus as detected by MRI.

Identifying preclinical signs of AD have been complemented by other research identifying individuals who would go on to progress to $\mathrm{AD}$ or convert from MCI to AD. One of the first studies observing this was by Oishi et al. (2011) who identified the fornix on an FA-scaled DTI map. FA reductions in this region predicted conversion form normal to amnestic MCI (aMCI) with a specificity of 1.0 and sensitivity of 0.67 and conversion from aMCI to $\mathrm{AD}$ with a specificity of 0.94 and sensitivity of 0.83 . This finding was termed "the fornix sign" and has shown promise as an early predictive imaging sign of AD (See Figures 1C,D). Two other studies similarly emphasized the use of fornix microstructure as a predictor of conversion. One study by Van Bruggen et al. (2012) retrospectively used DTI analysis to differentiate between a subgroup of aMCI who converted to $\mathrm{AD}$ and a subgroup that did not. They found that FA, DR, and DA changes within the fornix, cingulum, and the corpus callosum were able to significantly discriminate between the two diagnostic groups and therefore could be thought of as a predictor for conversion between MCI and AD. Another study by Douaud et al. (2013) compared two groups of MCI patients; one that converted to $\mathrm{AD}$ no earlier than from baseline scanning and another that remained stable without progression of symptoms for at least 3 years. Comparing both volumetric and microstructural variables including DTI anisotropy and diffusivity, they found significant group differences in the body of the fornix, left fimbria, and the superior longitudinal fasciculus. These studies emphasize 
the importance of microstructural integrity of the limbic lobe and specifically the fornix in predicting the progression/conversion from preclinical to clinical AD.

Recently, the field has been quite interested in identifying cognitively normal individuals who might be at increased risk for developing AD. The well-known and well-regarded hypothesis by Jack et al. and others that imaging changes are evident before clinical symptoms arise and that the pathological changes in the brain begin even decades before those has prompted increased interest in identifying these individuals (Morris et al., 1996; Bennett et al., 2006; Jack et al., 2010, 2013). In line with previous hypotheses that microstructural change precedes gross atrophic changes, there has been increasing work in using DTI and complimentary imaging methods to examine this. One study by Fletcher et al. (2013) identified the fornix as a region of microstructural change in cognitively normal elders. They found that the fornix body volume and DA were highly significant predictors of cognitive decline from normal cognition $[r==0.47(0.24-0.89), p=0.02$, and $r==1.25(1.02-1.46), p=0.005$, respectively]. This is one of the first studies establishing fornix degeneration as a predictor of incipient cognitive decline among healthy elderly individuals. Two studies conducted by Zhuang et al. (2012, 2013) demonstrated that WM changes in the fornix were evident in preclinical AD. One study (Zhuang et al., 2013) showed that when compared to

Table 1 | Summary of key biomarker research of the fornix in cognitively normal (NC), $\mathrm{MCl}$, and AD

\begin{tabular}{|c|c|c|c|}
\hline Study & Cohort & Regions of interest and imaging findings & Conclusion \\
\hline $\begin{array}{l}\text { Ringman } \\
\text { et al. (2007) }\end{array}$ & $\begin{array}{l}2 A D \\
21 \text { at-risk } A D\end{array}$ & $\begin{array}{l}\text { FA for mean whole brain WM, forniceal columns, } \\
\text { bilateral perforant pathways, left orbitofrontal lobe were } \\
\text { decreased relative to non-carriers }\end{array}$ & $\begin{array}{l}\text { FA is reduced in the fornix in persons carrying } \\
\text { mutations for } A D \text { prior to symptoms of dementia and is } \\
\text { a better predictor of mutation status than other regions }\end{array}$ \\
\hline $\begin{array}{l}\text { Mielke et al. } \\
\text { (2009) }\end{array}$ & $\begin{array}{l}25 \mathrm{NC} \\
25 \mathrm{MCl} \\
25 \mathrm{AD}\end{array}$ & $\begin{array}{l}\text { Lower FA in fornix, anterior cingulum bundle, splenium } \\
\text { of the corpus collosum in } A D \text { vs. } N C \text { and } A D \text { vs. } \mathrm{MCl}\end{array}$ & $\begin{array}{l}\text { FA is decreased in specific fiber tracts including the } \\
\text { fornix in } \mathrm{NC}, \mathrm{MCl} \text {, and } \mathrm{AD} \text { and may be an indicator of } \\
\text { progression over } 3 \text { months }\end{array}$ \\
\hline $\begin{array}{l}\text { Nowrangi } \\
\text { et al. (2013) }\end{array}$ & $\begin{array}{l}25 \mathrm{NC} \\
25 \mathrm{MCl} \\
25 \mathrm{AD}\end{array}$ & $\begin{array}{l}\text { Higher } \mathrm{MD} \text { and lower } \mathrm{FA} \text { in the fornix and splenium in } \\
\mathrm{AD} \text { vs. } \mathrm{MCl} \text { or } \mathrm{NC} \text { of } 12 \text { months }\end{array}$ & $\begin{array}{l}\text { Higher MD in the fornix longitudinally was a better } \\
\text { indicator of change than FA and may be an early } \\
\text { indicator of progression }\end{array}$ \\
\hline $\begin{array}{l}\text { Huang et al. } \\
(2012)\end{array}$ & $\begin{array}{l}24 \mathrm{NC} \\
11 \mathrm{aMCl} \\
26 \mathrm{AD}\end{array}$ & $\begin{array}{l}\text { FA, MD, DR, DA of limbic, commissural, and association } \\
\text { tracts are differentially associated with diagnostic } \\
\text { group. Comparison between aMCl and } \mathrm{NC} \text { show } \\
\text { differences only in limbic structures }\end{array}$ & $\begin{array}{l}\text { WM disruption of limbic tract structures is caused by } \\
\text { neuronal damage in aMCl and indicates a progression } \\
\text { pattern between WM tracts }\end{array}$ \\
\hline $\begin{array}{l}\text { Boespflug } \\
\text { et al. (2013) }\end{array}$ & $18 \mathrm{MCl}$ & $\begin{array}{l}\text { Lower DR, higher FA, and lower MD in the fornix } \\
\text { associated with better paired associate learning }\end{array}$ & $\begin{array}{l}\text { Disparate pathology of temporal stems and fornix WM } \\
\text { is associated with early memory impairment in } \mathrm{MCl}\end{array}$ \\
\hline $\begin{array}{l}\text { Oishi et al. } \\
\text { (2011) }\end{array}$ & $\begin{array}{l}25 \mathrm{NC} \\
24 \mathrm{aMCl} \\
23 \mathrm{AD}\end{array}$ & $\begin{array}{l}\text { Fornix sign differentiated } \mathrm{AD} \text { vs. } \mathrm{NC} \text { and predicted } \\
\text { conversion from } \mathrm{NC} \text { to } \mathrm{aMCl} \text { and from aMCl to } \mathrm{AD}\end{array}$ & The fornix sign may be a predictive biomarker sign of $A D$ \\
\hline $\begin{array}{l}\text { Van Bruggen } \\
\text { et al. (2012) }\end{array}$ & $\begin{array}{l}15 \mathrm{NC} \\
17 \mathrm{MCl} \text { (8 stable, } \\
9 \text { converters) } \\
15 \mathrm{AD}\end{array}$ & $\begin{array}{l}\text { Significant differences in FA and DR in the fornix, } \\
\text { corpus callosum, and cingulum in } \mathrm{MCl} \text { who remained } \\
\text { stable vs. converters }\end{array}$ & $\begin{array}{l}\text { DTI changes in } \mathrm{MCl} \text { converters vs. those who remained } \\
\text { stable may be an early indicator of progression to } A D\end{array}$ \\
\hline $\begin{array}{l}\text { Douaud et al. } \\
\text { (2013) }\end{array}$ & $\begin{array}{l}13 \text { aMCl } \\
\text { (converters) } \\
22 \text { aMCl (stable) }\end{array}$ & $\begin{array}{l}\text { Significant group differences in volume and } \\
\text { microstructure of left hippocampus, body of the fornix, } \\
\text { left fibria, and superior longitudinal fasciculus }\end{array}$ & $\begin{array}{l}\text { Microstructural changes in left hippocampus using DTI } \\
\text { showed most substantial differences between two } \\
\text { diagnostic groups and was best predictor of future } \\
\text { progression to AD }\end{array}$ \\
\hline $\begin{array}{l}\text { Fletcher et al. } \\
\text { (2013) }\end{array}$ & $102 \mathrm{NC}$ & $\begin{array}{l}\text { Fornix body volume and DA were highly significant } \\
\text { predictors of cognitive decline from normal cognition }\end{array}$ & $\begin{array}{l}\text { Fornix degeneration in NC may be a predictor of } \\
\text { incipient cognitive decline among healthy elderly } \\
\text { individuals }\end{array}$ \\
\hline $\begin{array}{l}\text { Zhuang et al. } \\
\text { (2012) }\end{array}$ & $\begin{array}{l}173 \mathrm{NC} \text { (stable) } \\
20 \mathrm{aMCl} \\
\text { (converted) }\end{array}$ & $\begin{array}{l}\text { aMCl converters had substantial reduction in FA in } \\
\text { precuneus, parahippocampal cingulum and gyrus, and } \\
\text { fornix while gray matter structures intact }\end{array}$ & $\begin{array}{l}\text { Microstructural WM changes are present in } \mathrm{NC} \text { in the } \\
\text { pre-aMCl stage and may be an imaging marker of early } \\
\text { AD-related brain changes }\end{array}$ \\
\hline $\begin{array}{l}\text { Zhuang et al. } \\
\text { (2013) }\end{array}$ & $\begin{array}{l}155 \mathrm{NC} \\
27 \text { "late" aMCl } \\
39 \text { "early" aMCl }\end{array}$ & $\begin{array}{l}\text { Late aMCI had lower WM integrity in the fornix, } \\
\text { parahippocampal cingulum, and uncinate fasciculus, } \\
\text { early aMCl showed white matter damage in fornix }\end{array}$ & $\begin{array}{l}\text { Limbic WM tracts preferentially affected in early stages } \\
\text { of cognitive dysfunction particularly in the fornix, which } \\
\text { may precede hippocampal atrophy }\end{array}$ \\
\hline
\end{tabular}


cognitively normal subjects and those with late MCI, early aMCI subjects had lower WM integrity in the fornix. In a second study (Zhuang et al., 2012), the same group showed that when compared to normal subjects who remained stable over 2 years, those who converted to aMCI had substantial reductions in WM integrity in the fornix, parahippocampal gyrus WM, and cingulum while gray matter structures remained relatively intact. FA was found to be a predictor of conversion from cognitively normal to aMCI. Taken together, these studies emphasize the continued importance of detecting earlier preclinical forms of $\mathrm{AD}$ even in normal subjects in order to identify patients who might benefit from interventional approaches. Table 1 summarizes the key studies described above.

\section{FORNIX AND CLINICAL TREATMENT IN AD}

One of the most recent and exciting avenues of research has been directed at enhancing cognition by stimulating or modulating fornix function. Deep Brain Stimulation (DBS) has been thought of for some time now as having significant effect on mood and anxiety disorders such as major depression, obsessive compulsive disorder as well as Gilles de Tourette's syndrome, and other conditions. Similarly, it has been hypothesized that DBS may also play a role in enhancing memory functions. One of the first studies in this area by Hamani et al. (2008) used DBS to stimulate the fornix/hypothalamus area in a man with morbid obesity. In a case observation report, they also described that the procedure generated detailed autobiographical memory. In $\mathrm{AD}$, this same concept has been hypothesized as being a potential therapeutic intervention for the treatment of amnesia and has just started being seriously studied. The first study of its kind, by Laxton et al. (2010), performed DBS stimulation of the fornix and hypothalamus in six AD patients. Though this was largely a safety study, the authors found that DBS triggered neural activity (increased metabolism) in some patients as seen through PET imaging (Laxton et al., 2010).

Later in vivo studies of DBS in patients with $\mathrm{AD}$ have been few and largely with relatively low $N$. Since 1985, there have been just two DBS studies targeting the stimulation of the fornix in patients with AD (Laxton et al., 2010; Fontaine et al., 2013). Found to over-all be safe, the clinical response has been rather modest with MMSE scores stabilizing rather than improving. However, reversal of AD-related hypometabolism has been observed in temporoparietal-occipital regions as well as increased connectivity between similar regions representing distributed cognitive networks (Smith et al., 2012). Given the lack of success thus far in developing pharmacological therapies for $\mathrm{AD}$ and the slow pace of further developments, such novel treatments as DBS is a promising avenue for therapy in AD. Currently, the Advance DBS clinical trial has recently completed recruitment of 42 participants with mild AD. Half of the study participants will have the stimulators turned on at the start of the study and the other half 12 months later. All participants will be followed for 18 months to track progression of their cognitive impairment. More information of this study can be found at www.clinicaltrials.gov.

\section{CONCLUSION}

There is a small but growing body of research directed toward the structure and function of the fornix in MCI and AD. Because of its important role within the "temporal lobe memory system," understanding the microstructural integrity of the fornix in MCI and $\mathrm{AD}$ has become an important area of focus in the field as there is a growing priority for identifying individuals early in the disease process and those who are at increased risk for progression or conversion. Recent studies have shown DTI is able to indirectly measure microstructural changes of the fornix that may precede gross atrophic changes of gray matter structures such as the hippocampus and entorhinal cortex. These studies demonstrate that DTI measurements of the fornix can significantly discriminate between cognitively normal, $\mathrm{MCI}$, and $\mathrm{AD}$ groups thereby serving as a robust biomarker of disease. Moreover, fornix measurements have been shown to be a reliable measure of conversion from preclinical disease to $\mathrm{AD}$. As pharmacological interventions continue to develop, studies of stimulating the fornix through DBS to alleviate or even reverse cognitive impairment has shown some early promise in stabilizing cognitive decline and increasing neural network activity.

\section{REFERENCES}

Aggleton, J. P., and Brown, M. W. (1999). Episodic memory, amnesia, and the hippocampal-anterior thalamic axis. Behav. Brain Sci. 22, 425-444. doi:10.1017/ S0140525X99002034 Discussion 444-489,

Baldwin, S., and Farias, S. T. (2009). Neuropsychological assessment in the diagnosis of Alzheimer's disease. Curr. Protoc. Neurosci. Chapter 10, Unit 10.3.

Bancher, C., Braak, H., Fischer, P., and Jellinger, K. A. (1993). Neuropathological staging of Alzheimer lesions and intellectual status in Alzheimer's and Parkinson's disease patients. Neurosci. Lett. 162, 179-182. doi:10.1016/0304-3940(93) 90590- $\mathrm{H}$

Basser, P. J., and Jones, D. K. (2002). Diffusion-tensor MRI: theory, experimental design and data analysis - a technical review. NMR. Biomed. 15, 456-467. doi:10.1002/nbm.783

Beaulieu, C., Does, M. D., Snyder, R. E., and Allen, P. S. (1996). Changes in water diffusion due to Wallerian degeneration in peripheral nerve. Magn. Reson. Med. 36, 627-631. doi:10.1002/mrm.1910360419

Behl, P., Stefurak, T. L., and Black, S. E. (2005). Progress in clinical neurosciences: cognitive markers of progression in Alzheimer's disease. Can. J. Neurol. Sci. 32, 140-151. doi:10.1017/S0317167100003917

Bennett, D. A., Schneider, J. A., Arvanitakis, Z., Kelly, J. F., Aggarwal, N. T., Shah, R. C., et al. (2006). Neuropathology of older persons without cognitive impairment from two community-based studies. Neurology 66, 1837-1844. doi:10.1212/01.wnl.0000219668.47116.e6

Bilir, E., Craven, W., Hugg, J., Gilliam, F., Martin, R., Faught, E., et al. (1998). Volumetric MRI of the limbic system: anatomic determinants. Neuroradiology 40, 138-144. doi:10.1007/s002340050554

Boespflug, E. L., Storrs, J., Sadat-Hossieny, S., Eliassen, J., Shidler, M., Norris, M., et al. (2013). Full diffusion characterization implicates regionally disparate neuropathology in mild cognitive impairment. Brain Struct. Funct. 219, 367-379. doi:10.1007/s00429-013-0506-x

Braak, H., Alafuzoff, I., Arzberger, T., Kretzschmar, H., and Del Tredici, K. (2006). Staging of Alzheimer disease-associated neurofibrillary pathology using paraffin sections and immunocytochemistry. Acta Neuropathol. 112, 389-404. doi:10. 1007/s00401-006-0127-z

Braak, H., and Braak, E. (1995). Staging of Alzheimer's disease-related neurofibrillary changes. Neurobiol. Aging 16, 271-278. doi:10.1016/0197-4580(95)00021-6 Discussion 278-284.,

Brewer, J. B., Gabrielli, J. D., Preston, A. R., Vaidya, C. J., and Rosen, A. C. (2003). "Memory," in Textbook of Clinical Neurology, ed. C. G. Goetz (Philadelphia, PA: Saunders).

Callen, D. J., Black, S. E., Gao, F., Caldwell, C. B., and Szalai, J. P. (2001). Beyond the hippocampus: MRI volumetry confirms widespread limbic atrophy in AD. Neurology 57, 1669-1674.

Cash, D. M., Ridgway, G. R., Liang, Y., Ryan, N. S., Kinnunen, K. M., Yeatman, T., et al. (2013). The pattern of atrophy in familial Alzheimer disease: volumetric MRI results from the Dian study. Neurology 81, 1425-1433. doi:10.1212/WNL.0b013e3182a841c6 
Cassel, J. C., Duconseille, E., Jeltsch, H., and Will, B. (1997). The fimbriafornix/cingular bundle pathways: a review of neurochemical and behavioural approaches using lesions and transplantation techniques. Prog. Neurobiol. 51, 663-716. doi:10.1016/S0301-0082(97)00009-9

Chao, L. L., Decarli, C., Kriger, S., Truran, D., Zhang, Y., Laxamana, J., et al. (2013). Associations between white matter hyperintensities and $\beta$ amyloid on integrity of projection, association, and limbic fiber tracts measured with diffusion tensor MRI. PLoS ONE 8:e65175. doi:10.1371/journal.pone.0065175

Copenhaver, B. R., Rabin, L. A., Saykin, A. J., Roth, R. M., Wishart, H. A., Flashman, L. A., et al. (2006). The fornix and mammillary bodies in older adults with Alzheimer's disease, mild cognitive impairment, and cognitive complaints: a volumetric MRI study. Psychiatry Res. 147, 93-103. doi:10.1016/j.pscychresns.2006. 01.015

Decarli, C. (2001). The role of neuroimaging in dementia. Clin. Geriatr. Med. 17, 255-279. doi:10.1016/S0749-0690(05)70068-9

Douaud, G., Menke, R. A., Gass, A., Monsch, A. U., Rao, A., Whitcher, B., et al. (2013). Brain microstructure reveals early abnormalities more than two years prior to clinical progression from mild cognitive impairment to Alzheimer's disease. J. Neurosci. 33, 2147-2155. doi:10.1523/JNEUROSCI.4437-12.2013

Fletcher, E., Raman, M., Huebner, P., Liu, A., Mungas, D., Carmichael, O., et al. (2013). Loss of fornix white matter volume as a predictor of cognitive impairment in cognitively normal elderly individuals. JAMA Neurol. 70, 1389. doi:10. 1001/jamaneurol.2013.3263

Fontaine, D., Deudon, A., Lemaire, J. J., Razzouk, M., Viau, P., Darcourt, J., et al. (2013). Symptomatic treatment of memory decline in Alzheimer's disease by deep brain stimulation: a feasibility study. J. Alzheimers Dis. 34, 315-323. doi:10.3233/JAD-121579

Gale, S. D., Burr, R. B., Bigler, E. D., and Blatter, D. (1993). Fornix degeneration and memory in traumatic brain injury. Brain Res. Bull. 32, 345-349. doi:10.1016/0361-9230(93)90198-K

Gold, B. T., Zhu, Z., Brown, C. A., Andersen, A. H., Ladu, M. J., Tai, L., et al. (2014). White matter integrity is associated with cerebrospinal fluid markers of Alzheimer's disease in normal adults. Neurobiol. Aging 35, 2263-2271. doi:10.1016/j.neurobiolaging.2014.04.030

Hamani, C., McAndrews, M. P., Cohn, M., Oh, M., Zumsteg, D., Shapiro, C. M., et al. (2008). Memory enhancement induced by hypothalamic/fornix deep brain stimulation. Ann. Neurol. 63, 119-123. doi:10.1002/ana.21295

Hopper, M. W., and Vogel, F. S. (1976). The limbic system in Alzheimer's disease. A neuropathologic investigation. Am. J. Pathol. 85, 1-20.

Huang, H., Fan, X., Weiner, M., Martin-Cook, K., Xiao, G., Davis, J., et al. (2012). Distinctive disruption patterns of white matter tracts in Alzheimer's disease with full diffusion tensor characterization. Neurobiol. Aging 33, 2029-2045. doi:10.1016/j.neurobiolaging.2011.06.027

Jack, C. R. Jr., Knopman, D. S., Jagust, W. J., Petersen, R. C., Weiner, M. W., Aisen, P. S., et al. (2013). Tracking pathophysiological processes in Alzheimer's disease: an updated hypothetical model of dynamic biomarkers. Lancet Neurol. 12, 207-216. doi:10.1016/S1474-4422(12)70291-0

Jack, C. R. Jr., Knopman, D. S., Jagust, W. J., Shaw, L. M., Aisen, P. S., Weiner, M. W., et al. (2010). Hypothetical model of dynamic biomarkers of the Alzheimer's pathological cascade. Lancet Neurol. 9, 119-128. doi:10.1016/S1474-4422(09) 70299-6

Kuzniecky, R., Bilir, E., Gilliam, F., Faught, E., Martin, R., and Hugg, J. (1999). Quantitative MRI in temporal lobe epilepsy: evidence for fornix atrophy. Neurology 53, 496-501. doi:10.1212/WNL.53.3.496

Laxton, A. W., Tang-Wai, D. F., McAndrews, M. P., Zumsteg, D., Wennberg, R., Keren, R., et al. (2010). A phase I trial of deep brain stimulation of memory circuits in Alzheimer's disease. Ann. Neurol. 68, 521-534. doi:10.1002/ ana.22089

Levy, J. A., and Chelune, G. J. (2007). Cognitive-behavioral profiles of neurodegenerative dementias: beyond Alzheimer's disease. J. Geriatr. Psychiatry Neurol. 20, 227-238. doi:10.1177/0891988707308806

McKhann, G., Drachman, D., Folstein, M., Katzman, R., Price, D., and Stadlan, E. M. (1984). Clinical diagnosis of Alzheimer's disease: report of the NINCDS-ADRDA work group under the auspices of department of health and human services task force on Alzheimer's disease. Neurology 34, 939-944. doi:10.1212/WNL.34.7.939

McKhann, G. M., Knopman, D. S., Chertkow, H., Hyman, B. T., Jack, C. R. Jr., Kawas, C. H., et al. (2011). The diagnosis of dementia due to Alzheimer's disease: recommendations from the national institute on aging-Alzheimer's association workgroups on diagnostic guidelines for Alzheimer's disease. Alzheimers Dement. 7, 263-269. doi:10.1016/j.jalz.2011.03.005

Mielke, M. M., Kozauer, N. A., Chan, K. C., George, M., Toroney, J., Zerrate, M., et al. (2009). Regionally-specific diffusion tensor imaging in mild cognitive impairment and Alzheimer's disease. Neuroimage 46, 47-55. doi:10.1016/j.neuroimage. 2009.01.054

Mori, S., Crain, B. J., Chacko, V. P., and Van Zijl, P. C. (1999). Three-dimensional tracking of axonal projections in the brain by magnetic resonance imaging. Ann. Neurol. 45, 265-269. doi:10.1002/1531-8249(199902)45:2<265::AID-ANA21> 3.0.CO;2-3

Morris, J. C., Storandt, M., McKeel, D. W. Jr., Rubin, E. H., Price, J. L., Grant, E. A., et al. (1996). Cerebral amyloid deposition and diffuse plaques in "normal" aging: evidence for presymptomatic and very mild Alzheimer's disease. Neurology 46, 707-719. doi:10.1212/WNL.46.3.707

Nieuwenhuys, R. (2008). “The human central nervous system," in The Human Central Nervous System, eds J. Voogd, C. Huijzen. 4th Edn (New York: Springer).

Nolte, J. (1993). "Origin and course of the fornix," in The Human Brain, 3rd Edn (St. Louis, MO: Mosby Yearbook).

Nowrangi, M. A., Lyketsos, C. G., Leoutsakos, J. M., Oishi, K., Albert, M., Mori, S., et al. (2013). Longitudinal, region-specific course of diffusion tensor imaging measures in mild cognitive impairment and Alzheimer's disease. Alzheimers Dement. 9, 519-528. doi:10.1016/j.jalz.2012.05.2186

Oishi, K., Mielke, M. M., Albert, M., Lyketsos, C. G., and Mori, S. (2011). The fornix sign: a potential sign for Alzheimer's disease based on diffusion tensor imaging. J. Neuroimaging 22, 365-374. doi:10.1111/j.1552-6569.2011.00633.x

Papez, J. W. (1995). A proposed mechanism of emotion. 1937. J. Neuropsychiatry Clin. Neurosci. 7, 103-112. doi:10.1176/jnp.7.1.103

Patestas Ma, G. L. (2006). "Limbic system," in A Textbook of Neuroanatomy, ed. L. P. Gartner (Oxford: Blackwell), 344-359.

Pierpaoli, C., Jezzard, P., Basser, P. J., Barnett, A., and Di Chiro, G. (1996). Diffusion tensor MR imaging of the human brain. Radiology 201, 637-648. doi:10.1148/radiology.201.3.8939209

Racine, A. M., Adluru, N., Alexander, A. L., Christian, B. T., Okonkwo, O. C., Oh, J., et al. (2014). Associations between white matter microstructure and amyloid burden in preclinical Alzheimer's disease: a multimodal imaging investigation. Neuroimage Clin. 4, 604-614. doi:10.1016/j.nicl.2014.02.001

Ringman, J. M., O’Neill, J., Geschwind, D., Medina, L., Apostolova, L. G., Rodriguez, Y., et al. (2007). Diffusion tensor imaging in preclinical and presymptomatic carriers of familial Alzheimer's disease mutations. Brain 130, 1767-1776. doi:10.1093/brain/awm 102

Roher, A. E., Weiss, N., Kokjohn, T. A., Kuo, Y. M., Kalback, W., Anthony, J., et al. (2002). Increased A beta peptides and reduced cholesterol and myelin proteins characterize white matter degeneration in Alzheimer's disease. Biochemistry 41, 11080-11090. doi:10.1021/bi026173d

Shahani, S. K., Lingamaneni, R., and Hemmings, H. C. Jr. (2002). General anesthetic actions on norepinephrine, dopamine, and gamma-aminobutyric acid transporters in stably transfected cells. Anesth. Analg. 95, 893-899. doi:10.1097/ 00000539-200210000-00019

Smith, G. S., Laxton, A. W., Tang-Wai, D. F., McAndrews, M. P., Diaconescu, A. O., Workman, C. I., et al. (2012). Increased cerebral metabolism after 1 year of deep brain stimulation in Alzheimer disease. Arch. Neurol. 69, 1141-1148. doi:10.1001/archneurol.2012.590

Song, S. K., Kim, J. H., Lin, S. J., Brendza, R. P., and Holtzman, D. M. (2004). Diffusion tensor imaging detects age-dependent white matter changes in a transgenic mouse model with amyloid deposition. Neurobiol. Dis. 15, 640-647. doi:10.1016/j.nbd.2003.12.003

Song, S. K., Sun, S. W., Ju, W. K., Lin, S. J., Cross, A. H., and Neufeld, A. H. (2003). Diffusion tensor imaging detects and differentiates axon and myelin degeneration in mouse optic nerve after retinal ischemia. Neuroimage 20, 1714-1722. doi:10.1016/j.neuroimage.2003.07.005

Thies, W., Bleiler, L., and Alzheimer's, A. (2013). 2013 Alzheimer's disease facts and figures. Alzheimers Dement. 9, 208-245. doi:10.1016/j.jalz.2013.02.003

Thomas, A. G., Koumellis, P., and Dineen, R. A. (2011). The fornix in health and disease: an imaging review. Radiographics 31, 1107-1121. doi:10.1148/rg. 314105729

Van Bruggen, T., Stieltjes, B., Thomann, P. A., Parzer, P., Meinzer, H. P., and Fritzsche, K. H. (2012). Do Alzheimer-specific microstructural changes in mild cognitive impairment predict conversion? Psychiatry Res. 203, 184-193. doi:10.1016/j.pscychresns.2011.12.003 
Xu, J., Chen, S., Ahmed, S. H., Chen, H., Ku, G., Goldberg, M. P., et al. (2001). Amyloid-beta peptides are cytotoxic to oligodendrocytes. J. Neurosci. 21, Rc118.

Xu, Y., Jack, C. R. Jr., O’brien, P. C., Kokmen, E., Smith, G. E., Ivnik, R. J., et al. (2000). Usefulness of MRI measures of entorhinal cortex versus hippocampus in AD. Neurology 54, 1760-1767. doi:10.1212/WNL.54.9.1760

Yamada, K., Shrier, D. A., Rubio, A., Yoshiura, T., Iwanaga, S., Shibata, D. K., et al. (1998). MR imaging of the mamillothalamic tract. Radiology 207, 593-598. doi:10.1148/radiology.207.3.9609878

Zhuang, L., Sachdev, P. S., Trollor, J. N., Kochan, N. A., Reppermund, S., Brodaty, H., et al. (2012). Microstructural white matter changes in cognitively normal individuals at risk of amnestic MCI. Neurology 79, 748-754. doi:10.1212/WNL. 0b013e3182661f4d

Zhuang, L., Sachdev, P. S., Trollor, J. N., Reppermund, S., Kochan, N. A., Brodaty, H., et al. (2013). Microstructural white matter changes, not hippocampal atrophy, detect early amnestic mild cognitive impairment. PLoS ONE 8:E58887. doi:10.1371/journal.pone.0058887
Conflict of Interest Statement: The authors declare that the research was conducted in the absence of any commercial or financial relationships that could be construed as a potential conflict of interest.

Received: 01 September 2014; accepted: 02 January 2015; published online: 21 January 2015.

Citation: Nowrangi MA and Rosenberg $P B$ (2015) The fornix in mild cognitive impairment and Alzheimer's disease. Front. Aging Neurosci. 7:1. doi: 10.3389/fnagi.2015.00001

This article was submitted to the journal Frontiers in Aging Neuroscience.

Copyright (C) 2015 Nowrangi and Rosenberg. This is an open-access article distributed under the terms of the Creative Commons Attribution License (CC BY). The use, distribution or reproduction in other forums is permitted, provided the original author(s) or licensor are credited and that the original publication in this journal is cited, in accordance with accepted academic practice. No use, distribution or reproduction is permitted which does not comply with these terms. 